\title{
CORPO COMO MORADA: UMA HISTÓRIA DE LUTA POR MORADIA
}

\author{
Marcela Boni Evangelista ${ }^{1}$
}

\begin{abstract}
Resumo
O presente artigo é resultado de uma iniciativa coletiva das pesquisadoras do Grupo de Pesquisa em Gênero e História do Departamento de História da USP. A partir de ações que buscavam ir além das discussões teóricas, o grupo iniciou um processo de aproximação de mulheres militantes da luta por moradia em São Paulo. A partir deste contato, foram realizadas entrevistas de história oral de vida, sendo que a primeira delas foi o mote para a reflexão aqui apresentada. Busca-se valorizar, por meio da narrativa de uma liderança do movimento, a experiência compartilhada pelas mulheres que lutam por melhores condições de vida nas periferias das grandes cidades.
\end{abstract}

Palavras-chave: Mulheres; Moradia; História Oral.

\begin{abstract}
This article is the result of a collective initiative by researchers from the Research Group on Gender and History of the USP Department of History. Based on actions that sought to go beyond theoretical discussions, the group started a process of bringing women activists closer to the struggle for housing in São Paulo. Based on this contact, oral life history interviews were conducted, the first of which was the motto for the reflection presented here. It seeks to enhance, through the narrative of a leadership of the movement, the experience shared by women who struggle for better living conditions on the outskirts of large cities.
\end{abstract}

Keywords: Women; Housing; Oral History

\footnotetext{
${ }^{1}$ Possui Graduação (2005), Mestrado (2011) e Doutorado (2017) em História pela USP. Atualmente é coordenadora do Núcleo de Estudos de História Oral (NEHO-USP) e pesquisadora do Grupo de Pesquisa em Gênero e História da USP (GRUPEG-HIST). E-mail: marcela.boni@gmail.com
} 
Fazenda velha

Cumieira arriô...

Levanta povo

Cativeiro acabou...

Se o povo soubesse o talento que ele tem

Não aturava desaforo de ninguém... ${ }^{2}$

Muitas são as lutas empreendidas por mulheres ao longo da História. E por mais que falemos desde o agora, há inúmeros pontos de convergência que nos levam à indagação: por que lutam as mulheres?

De maneira muito simplificada, poderíamos dizer que pelo corpo e pela casa: seu corpo e os corpos dos seus; a sua casa, que geralmente é também a dos seus.

É quase sempre uma luta que começa no individual, mas que resvala no coletivo. As manifestações sobre a carestia de gêneros alimentícios, que não somente lhes proviam, mas aos filhos, sobretudo, são exemplos de lutas lideradas por mulheres em diferentes tempos e espaços. Segundo Michelle Perrot "Os motins por alimentos, grande forma de motim popular ainda no século XIX, são quase sempre desencadeados e animados pelas mulheres. ${ }^{3 \text { ", }}$

Os dilemas do corpo, da sexualidade e da reprodução, por sua vez, interferem diretamente em anseios que vão além do individual. Mais uma vez, temos as mulheres em linha de frente para lutar por direitos que lhes permitam vivenciar a liberdade sexual, a maternidade saudável e relações de gênero menos desiguais.

A desigualdade, longe de ser natural, é posta pela tradição cultural, pelas estruturas de poder, pelos agentes envolvidos na trama de relações sociais. Nas relações entre homens e mulheres, a desigualdade de gênero não é dada, mas pode ser construída, e o é, com frequência ${ }^{4}$.

Não é novidade que às mulheres é relegada a responsabilidade pela casa, pelo privado. Ainda que em termos mais gerais remeta à individualidade burguesa, uma vez

\footnotetext{
2 Trecho de cantiga entoada pela narradora durante a entrevista.

${ }^{3}$ PERROT, Michelle. Os excluídos da História: operários, mulheres, prisioneiros. Rio de Janeiro: Paz e Terra, 2001.

${ }^{4}$ SAFFIOTI, Heleieth. Gênero, patriarcado, violência. São Paulo: Expressão Popular: Fundação Perseu Abramo, 2015.
} 
que as mulheres das classes populares sempre estiveram "na rua" exercendo diversos tipos de trabalhos, a dicotomia público e privado perpassa outras conjunturas.

A luta por moradia, nesse sentido, se refere à busca de um espaço privado, teoricamente de domínio feminino. Mas o que dizer das mulheres que não o possuem? Querem ter "um teto todo seu" ou apenas uma casa para abrigar os seus? Em contexto marcado pela disputa por espaços e acolhimento, a casa pode ser mais que um cômodo, um quarto... Pode ser o próprio corpo!

\section{O projeto "Corpo como Morada"}

O projeto "Corpo como morada" se articulou a partir do Grupo de Pesquisa em Gênero e História ${ }^{5}$, que identificou entre suas integrantes o ímpeto de extrapolar de alguma forma as discussões teóricas. Aproveitando contatos de pessoas conhecidas da coordenadora Stella Franco com mulheres do MTST, teve início um processo de aproximação que, inicialmente, não tinha desdobramento definido para além da já promissora troca de experiências. A primeira "ponte" que nos conectou com as mulheres do movimento foi Renata Del Monaco, geógrafa e educadora cujo olhar sensível e atuação junto ao grupo, foi indispensável para os contatos estabelecidos.

Luciana Silva ${ }^{6}$ foi, desde o princípio, a porta-voz das mulheres militantes e a riqueza de seu ativismo e trajetória mobilizou as pesquisadoras a delinearem um projeto em que as histórias de luta daquelas mulheres encontrassem evidência.

Com isso, a opção pelo registro de histórias de vida com base nos procedimentos da história oral foi considerada adequada para alcançar o objetivo central desta iniciativa: dar visibilidade às trajetórias de mulheres que lutam por moradia, enfatizando sua criatividade e força em detrimento de uma vitimização simplificadora.

\footnotetext{
História oral de vida é gênero bastante cultivado e com crescente público. Trata-se de narrativa com aspiração de longo curso - daí o nome "vida" - e versa sobre aspectos continuados da experiência de pessoas. Trata-se de um tipo de narração com começo, meio e fim, em que momentos extremos origem e atualidade - tendem a ganhar lógica explicativa ${ }^{7}$.
}

\footnotetext{
${ }^{5}$ O GRUPEGH (Grupo de Pesquisa em Gênero e História) foi criado em 2015 como desdobramento da oferta da disciplina "História das Relações de Gênero" no Departamento de História da USP. Coordenado pela Profa. Dra. Stella Maris Franco e pela Pesquisadora Doutora Júlia Glaciela Oliveira, realiza reuniões mensais voltadas para a discussão teórica e atividades complementares dentro e fora da Academia.

${ }^{6}$ Entrevista realizada em 16 de junho de 2018, na ocupação Copa do Povo, em Itaquera - SP.

${ }^{7}$ MEIHY, José Carlos Sebe Bom. RIBEIRO, Suzana Lopes Salgado. Guia Prático de História Oral. São Paulo: Contexto, 2011.
} 
Evidente que não se pretende extrair as responsabilidades políticas ou o sofrimento do grupo e sua vulnerabilidade, mas o que se pretende é ir além de percepções cristalizadas e pouco próximas da realidade de onde surgem as narrativas. O projeto, neste sentido, tomou corpo tendo em vista a possibilidade de registrar, por meio de entrevistas em áudio, as histórias de vida e de luta de mulheres engajadas no grupo e envolvidas com a organização da Ocupação Teresa de Benguela, situada na região leste da cidade de São Paulo.

A ocupação fora visitada por um grupo de pesquisadoras do GRUPEGH durante evento que mobilizou, além das organizadoras da ocupação, pesquisadoras da área da saúde e do direito, com o objetivo de atender à grande demanda de mulheres em situação de vulnerabilidade residentes nas adjacências, naquela ocasião, sobretudo mulheres grávidas, pois tratava-se de um chá de fraldas coletivo.

Este pode ser considerado o primeiro contato oficial entre o grupo de pesquisadoras da Universidade e militantes, sendo oportunidade de aproximação com diversas mulheres que participam há muitos anos de movimentos de luta por moradia e que, naquele momento, integravam o MTST. As conversas foram informais e, a cada breve contato, uma indicava outra companheira que também tinha muito a dizer sobre aquela realidade. Uma lista de nomes e contatos foi delineada para que pudéssemos definir os próximos passos do projeto.

Diante das condições objetivas para a condução da proposta inicial, foram consideradas especialmente as que diziam respeito à disponibilidade das colaboradoras da pesquisa que, em seu cotidiano, conciliavam afazeres domésticos, de trabalho e da militância. Além disso, era preciso observar a distância geográfica das ocupações, bem como a viabilidade da recepção das pesquisadoras para a realização de entrevistas gravadas.

Neste aspecto, importa ressaltar a necessidade de ambiente minimamente confiável para a narração de episódios marcados por subjetividades e intimidade, onde também seja possível garantir, dentro do possível, a qualidade da gravação em áudio. Aspectos técnicos e éticos que compõem de maneira central a condução de projetos de história oral de vida.

Novas reuniões em grupo foram realizadas para organizar a primeira sessão de gravações. Devido à dificuldade de conciliar as disponibilidades de colaboradoras e pesquisadoras, decidiu-se compor uma equipe de quatro pesquisadoras para desempenhar o registro de duas entrevistas simultaneamente. O local designado por Luciana, nossa 
colaboradora-mediadora, foi a Ocupação Copa do Povo, também localizada na zona leste da capital paulista. $\mathrm{O}$ espaço, por sua vez, garantia as condições necessárias para a realização das entrevistas, as quais foram feitas em dupla pelas pesquisadoras.

Enquanto Marcela Boni e Aline Maciel entrevistavam Luciana Silva no espaço maior de um dos barracões da ocupação, Stella Franco e Mariana Saccon faziam o registro da história de Maria Helena Benites, mais conhecida como "tia Helena", em uma sala reservada no mesmo local. Depois desta fase, viriam os procedimentos textuais de transcrição e textualização, para que novas etapas fossem delineadas. No entanto, em função da dinâmica bastante intensa do movimento de luta por moradia, que envolve inúmeras ações, desde reuniões até ocupações de novos espaços, o projeto precisou ser interrompido por tempo indeterminado, o que não impediu que os registros feitos pudessem mobilizar reflexões como a que aqui é apresentada.

Para este artigo, partimos da entrevista realizada com Luciana, cuja escuta representou a possibilidade de identificar elementos previamente inferidos e, ao mesmo tempo, de nos surpreendermos diante da profundidade de significados de sua atuação individual e coletivamente.

\section{Morada: o lugar onde o corpo se sente em casa}

A luta por moradia adquire significados múltiplos no mundo em que vivemos. Pode ser a luta pela casa própria por aqueles que podem pagar aluguel; pode ser aquela que se experimenta por quem foi retirado de uma casa que fora sua; e pode ser de quem sabe o esforço de construir algo, que comece por uma parede e que, aos poucos, ganha contornos de casa.

No caso de Luciana, a primeira experiência nesse sentido se deu ainda em família, ao presenciar o trabalho de fazer existir uma casa onde antes havia o vazio. Força física, dedicação, criatividade e apoio de todos que se fazem presentes. Assim, a primeira casa de que nos contou foi feita, ainda, pelas mãos de seus pais.

\footnotetext{
Nasci em São Paulo em 1975, numa época de ditadura no Brasil. Meu pai conta que naquela época sofria muito preconceito por ser preto e ter filhos doentes. Por conta da situação da minha mãe, alguns dos meus irmãos nasceram saudáveis e outros não. Meus pais foram morar de favor na casa da Tia Dolores, que era uma mulher perversa! Para fazer comida, tinha que ser no querosene e só podia lavar roupa de sexta-feira, quando minha tia ligava a água. Por causa disso, meu pai foi até a delegacia pedir para invadir uma casa. O delegado pensou que ele fosse maluco, afinal estava pedindo para cometer um crime! É até engraçado onde o desespero pode nos levar! E foi com essa situação que se juntou a um grupo de pessoas que pegaram um terreno vazio e construíram um barraco para morar.
} 
Eles começaram a construir e batizaram a favela de Piracaia, em Penha de França. Eu era muito pequena, a filha mais nova até aquele momento, mas tenho algumas recordações como de que lá tinha banheiro coletivo, então todo mundo usava... Nessa época também tinha um movimento chamado "Panela Vazia", contra a carestia e apareciam jovens estudantes para falar com os moradores.

Diferente do que se possa imaginar em relação à população menos favorecida como sendo passiva e dependente, as organizações de bairro e voltadas para melhores condições de vida aparecem nos mais diferentes contextos históricos. Em comum, a participação ativa de mulheres:

Como estão prontas para se amotinar, a transmitir a senha que mobiliza imediatamente a comunidade das mulheres! Elas muitas vezes levam os filhos, dando-lhes um papel: ficar de olho, levar mensagem, dar o sinal de alerta ${ }^{8}$.

Essas são ocasiões que dão os contornos de um cotidiano repleto de atividades que vão além dos interesses individuais e ocupam os espaços da casa para refletir e agir em função de demandas coletivas. Os filhos pequenos muitas vezes acabam fazendo parte desse cenário, o que os conduz, no futuro, a comportamentos equivalentes, como foi o caso de Luciana.

Lembro que tinha muita enchente! Minha mãe me colocava encima da mesa, no lugar mais alto possível! As reuniões aconteciam no nosso barraco e não sei exatamente do que falavam, mas possivelmente era contra a carestia, em favor da redução dos preços dos alimentos, que naquela época era tudo muito caro! Era difícil ter acesso às coisas. Meus pais participavam disso e eu ia junto. Até que fomos para outro lugar, num projeto de moradia do $\mathrm{BNH}$, que chamava embrião, tinha cozinha e banheiro. Passamos o natal lá na Cidade Tiradentes, que ainda nem esse nome tinha, só passou a chamar assim quando ampliou tudo. Dizem que a Cidade Tiradentes tem 34 anos, mas tem mais se contar do bairro onde fomos depositados.

Sua trajetória integra a história da ocupação de áreas da periferia de São Paulo e não difere de tantas outras. Assim como um organismo vivo, os pequenos cômodos construídos com alicerces de precariedade vão, com o tempo, adquirindo novas formas e novos membros, chegando em construções cuja complexidade reflete o crescimento urbano, as mudanças na paisagem, a dinâmica das famílias menos favorecidas. Estas, sem maiores oportunidades de acesso à moradia, acabam crescendo de forma mais ou menos organizada em terrenos que aos poucos são moldados por novas paredes, tetos e corpos.

Meus pais morreram, mas a casa deles continua lá até hoje com as outras gerações. Dos sete filhos deles, eu e mais um seguimos na luta por moradia, na verdade nunca paramos, sempre estivemos no movimento por moradia de alguma forma. Nossa casa, que tinha só um cômodo, hoje tem onze! A família foi se reproduzindo e a casa foi junto... Hoje mora lá uma irmã que já tem filhos

\footnotetext{
${ }^{8}$ PERROT, Michelle. Os excluídos da História: operários, mulheres, prisioneiros. Rio de Janeiro: Paz e Terra, 2001.
} 
e que a filha está grávida de uma menina. Essa é a realidade de muitas famílias. Não arrisco uma porcentagem, mas na Cidade Tiradentes é muito comum morarem várias gerações no mesmo espaço. No nosso caso foi um pouco diferente por conta da educação e da militância por outras pessoas.

Em sua especificidade, vem o que fica dentro de casa, ou seja, a subjetividade, os conflitos, pai e mãe em disputa. Ao contar a história de sua mãe, que tentou um destino diferente da avó - cuja trajetória fora marcada por abusos e violações -, acaba por descrever outra história repleta de decepções e desigualdades de gênero, em que o corpo da mulher fica submetido aos desmandos do marido. O resultado acaba refletindo na própria relação com os filhos, que somente na vida adulta conseguem compreender as atitudes maternas.

\begin{abstract}
Minha mãe tentou fazer diferente e casou com um homem pela cor. Ela achou que meu pai tinha a cor igual e, na cabeça dela, isso não a faria sofrer tanto. Mas foi totalmente o oposto! Meu pai fez tudo que um machista faz! Não deixava minha mãe tomar anticoncepcional porque mulher que faz isso é quem trai o marido. Ele era alcoólatra e teve caso com outras mulheres. A gente só soube quando ele faleceu em 2015. Ele teve filho com outra mulher, mas minha mãe nem sabia. Ela não tinha amigas... Nós éramos suas amigas... Na época eu me aborrecia quando ela queria brigar, preferia até apanhar, mas hoje entendo que ela só queria conversar. Ela não tinha ninguém e pegava a gente de "orelhada" para falar o dia inteiro sobre as coisas...
\end{abstract}

Embora cada família tenha sua história, é possível compreender que este caso revela muitas semelhanças com a de tantas mulheres! Relacionamentos desiguais, abusivos, marcados pelo alcoolismo e por frustrações. Nem sempre, contudo, quem os protagoniza assim os interpreta.

\begin{abstract}
Com efeito, paira sobre a cabeça de todas as mulheres a ameaça de agressões masculinas, funcionando isto como mecanismo de sujeição aos homens, inscrito nas relações de gênero. Embora se trate de mecanismos de ordem social, cada mulher o interpretará singularmente. Isso posto, a ruptura de integridades como critério de avaliação de um ato violento situa-se no terreno da individualidade 9 .
\end{abstract}

Interessa-nos considerar o aspecto subjetivo das relações que se estabelecem entre homens e mulheres e as transformações que o tempo e o convívio com diferentes realidades impõem às mudanças comportamentais. Luciana se revoltava com o que via em casa, enquanto a mãe conseguia enxergar alguma vantagem em seu relacionamento se comparado com o que tinha vivido a avó materna. A exposição à violência de gênero não se extingue por completo, mesmo passadas as gerações. No entanto, a cada camada de vivência se somam novas formas de compreender a própria existência.

\footnotetext{
${ }^{9}$ SAFFIOTI, Heleieth. Gênero, patriarcado, violência. São Paulo: Expressão Popular: Fundação Perseu Abramo, 2015.
} 


\section{Sair de casa: em busca da própria morada}

Não é fácil conviver com aquilo que não se concorda. Os espaços pequenos e conflituosos e a vida que urge fizeram Luciana sair daquela casa da família e buscar uma casa sua.

Com 16 anos comecei a namorar o pai das minhas filhas, com quem me casei. Mas era um relacionamento abusivo, com traição e não deu certo. Tive que voltar para a casa da mãe, agora com as duas filhas. Foi então que entrei para o movimento de moradia no Barro Branco, onde moro há 18 anos! É muito gratificante dizer que construí a minha casa! Eu e outras mulheres! Os homens se vangloriavam de serem os técnicos que sabiam de tudo e a gente ficava com o trabalho de encher os carrinhos, buscar água no poço, pegar ferramenta e eu não achava isso certo. Foi por isso que briguei mesmo e falei que queria aprender!

Já experiente no processo de construção de uma casa em termos objetivos, foi em busca de liberdade e de um teto só seu. Vivenciar o cotidiano de movimentos de moradia a colocou em posição favorável para construir sua própria casa e assim o fez.

Interessante pensar sobre os diferentes significados que adquire a expressão "um teto todo seu”. Imortalizada por Virgínia Woolf, que postulava a necessidade de liberdade e independência financeira para que as mulheres atingissem a idealidade necessária para a criação, quando acionada para palestrar sobre as mulheres e a ficção, assim se posicionou:

Tudo que eu poderia fazer seria dar-lhes minha opinião sob um ponto de vista mais singelo: uma mulher precisa ter dinheiro e um teto todo seu, um espaço próprio, se quiser escrever ficção ${ }^{10}$.

No caso de Luciana, temos necessidades que vão além da escrita criativa e se projetam à ideia de sobrevivência, ou talvez ao acesso a uma vida digna, pautada no direito à moradia e na observância da cidadania. Mas isso tampouco significa que a possibilidade da escrita se esvai. O exemplo de Carolina Maria de Jesus, neste caso, nos parece algo no meio dessas duas percepções sobre a casa, o teto e a liberdade, configurando a relevância de se considerar as subjetividades que permeiam as trajetórias individuais, mas que também ampliam visões coletivas.

Carolina escreveu o "Diário de uma favelada", que posteriormente se tornou um best seller e apontou para a necessidade de desnaturalizar a noção de que a pobreza impede o desenvolvimento da criatividade. Carolina Maria de Jesus disse "Quando eu

\footnotetext{
${ }^{10}$ WOOLF, Virgínia. Um teto todo seu. São Paulo: Tordesilhas, 2014.
} 
não tinha nada que comer, em vez de xingar, eu escrevia”. E é justamente sobre a vida precária de catadora e moradora de favela que escrevia em seu diário.

Luciana, por sua vez, buscava tijolo a tijolo, a cada espaço edificado um significado. E assim como antes precisou de um lugar, abriu as portas de sua casa simples, imperfeita e incompleta para quem mais precisasse de abrigo.

\begin{abstract}
Mas assim era minha casa, tipo aquela casa "muito engraçada, que não tinha teto, não tinha nada..." Lá era muito apertado para tanta gente, que acabava tirando a privacidade e a necessidade uns dos outros. De qualquer jeito, o mutirão deixou muito a desejar porque sei que é errado cobrarem dinheiro da gente e mais ainda eu ter que sair com o coordenador para não ser cortada, algo que nem poderia comentar. Era obrigada a transar com ele e ainda ir nas reuniões de partido me apresentando como "dama de companhia", sei lá como se fala. Eu tinha nojo daquilo tudo e mesmo hoje, estando no MTST, não gosto de relação com nenhum partido político. Gosto de política, isso sim, mas de partido, nenhum!
\end{abstract}

Mas ter espaço para construir não era algo simples e o mutirão, que logo se conformaria em movimento organizado demandava atitudes diferenciadas. Os homens, sempre à frente, decidiam muitas coisas, dentre as quais quem teria os melhores espaços. Ser privilegiada naquele contexto, por sua vez, representou se submeter a situações que não queria. A violação que, para quem está de fora é nítida, foi somente aos poucos sendo percebida por Luciana que, sentiu na pele e no dia a dia o que precisava fazer e deixar de ser para ascender. Ser submetida às condições de um líder de mutirão ou movimento foi momento para compor o ser que viria a existir.

As relações de autoridade que produzem a subordinação das mulheres são tecidas por múltiplos fatores. A dupla moral sexual, a tolerância à violência que as atinge por serem mulheres, a ideologia maternalista e os limites para o controle autônomo da sua capacidade reprodutiva são alguns deles ${ }^{11}$.

Mas quem nasceu para protagonizar não está na vida por acaso. Luciana buscou entre desmandos e violações a força para se desorganizar. E se reorganizar. Para além do ímpeto pessoal, sua experiência de vida familiar e pessoal foi ingrediente para elaborar novas formas de atuação diante do movimento que se fez em sua frente.

Ainda sem saber ou mensurar o potencial de um movimento organizado, partiu para o que, de individual, lhe gritava o coletivo. Ali sim havia a chance de ampliar o desejo íntimo pela casa, a casa de que todos e todas precisam, mas que demandava atitudes de luta para se fazer valer. Entrar para um movimento social organizado parecia destino óbvio, mas faltava ainda uma luta específica. Aquela que lhe representasse e àquelas com quem se identificava.

${ }^{11}$ BIROLI, Flávia. Gênero e Desigualdades: limites da democracia no Brasil. São Paulo: Boitempo, 2018. 
Foi assim que construí minha casa, onde moro até hoje! E construímos a casa de muita gente. Funcionava assim: a cada quadra, a gente fazia a alvenaria de todas as casas; depois a parte hidráulica, que é o sistema de água e esgoto. Mas da quadra onde eu morava não fizeram nada disso, então eu tive que fazer tudo. Deram o material e "se vira". Ainda bem que tive a ajuda de um amigo, que era eletricista do mutirão, e a gente dava um troco e ele fazia um "gato" para a gente. $\mathrm{O}$ que ele fez está na minha casa até hoje.

Mudei para minha casa no dia 2 de fevereiro de 2000. De lá para cá muita coisa mudou! Já fiz duas reformas! Antes tinha dois quartos e um banheiro bem pequeno. Eu fiz mais um quarto e dois banheiros, um verde que vou pintar de bege e um salmão. A sala é bem grande e tem a cozinha e a garagem. Apesar da violência que passei e que hoje luto para que não ocorra com outras mulheres, por conta disso tive um certo privilégio porque o coordenador me permitiu escolher onde queria morar, sem precisar de sorteio. Moro onde eu quis porque, como tinha duas meninas, não queria morar na avenida, queria que elas tivessem uma pracinha para brincar. Nossa casa fica em frente a uma pracinha e parece a "Vila do Chaves", um condomínio que teve até projeto. Todo mundo que vai gosta e acha bonitinho. As árvores que estão lá, plantei junto com as crianças.

Mulheres que, como ela, lutavam pela casa, por uma casa que lhes conferisse autonomia, onde pudessem criar os filhos e ter alguma liberdade. Para isso deveria servir o engajamento em um movimento social que, segundo o Dicionário Crítico do Feminismo, no verbete assinado por Josette Trat:

É considerar igualmente que todo movimento social é "sexuado", não somente em função do sexo biológico de seus/suas participantes, mas antes de tudo porque reflete - e às vezes questiona - a divisão sexual do trabalho e as relações de poderes entre homens e mulheres na sociedade ${ }^{12}$.

Não era só a luta por moradia, essa encampada por mulheres e homens desprovidos de um direito básico. Mas uma luta específica, das mulheres que, por condições muito particulares, precisavam de sua luta e de um direito por muitos postulado, mas por poucos levado a cabo.

Era preciso que fosse dedicado um olhar diferenciado para as mulheres e, então, veio o feminismo que, no início, para ela nem esse nome tinha, mas que no seu âmago possuía o sentido intrínseco de lutar pelas mulheres em sua especificidade. Mulheresmães, solteiras, abandonadas pelos companheiros e pela agrura da pobreza e da negritude, pelo que hoje chamamos marcadores sociais da diferença ou, ainda, interseccionalidades.

\footnotetext{
Minha entrada para o movimento foi, adivinhem? Através de uma mulher! Fazia dois anos que não saía de casa, a não ser para ir ao médico. Até que num dia como esse, em junho de 2014 as coisas começaram a mudar. Com a Copa do Mundo, por causa da construção do estádio em Itaquera, teve muito despejo de famílias que moravam nas comunidades. O MTST veio para cá fazer essa ocupação, na época com oito mil acampados.
}

\footnotetext{
12 TRAT, Josette. Movimentos Sociais. In: HIRATA, Helena; LABORIE, Françoise; LE DOARÉ, Hélène;
} SENOTIER, Danièle (Orgs). Dicionário Crítico do Feminismo. São Paulo: Editora UNESP, 2009. 
Veio então o cotidiano de ocupações sem fim. E em quantas delas não estavam reproduzidas as desigualdades de gênero? Esses termos, ainda desconhecidos por Luciana, se faziam visíveis em inúmeros casos de violência do Estado e da misoginia. O machismo identificado e logo assim denominado fez de nossa protagonista uma militante não somente do movimento por casas, mas por mulheres.

Sua luta, que ainda não se dizia feminista, era pelas mulheres que não tinham um teto todo seu e nem ao menos dividido com alguém. Eram mulheres que, assim como ela, tiveram situações mais ou mesmo favoráveis de viver com ou sem alguém, que nessas trajetórias se tornaram mães e que precisavam, mais que desejavam, de um lugar para cuidar dos seus. E de si.

E assim ocupações foram dando forma a algo além do universo da casa, mas que pretenderam ser mais que isso. Lugares abandonados se transformando em espaços de acolhimento de quem precisava não apenas de espaço, mas de afago. Não apenas de comida, mas de conforto, de compreensão. Tereza de Benguela é o nome de uma mulher que lutou e que teve seu nome dedicado a um espaço de reflexão e acolhimento de tantas outras mulheres que não tinham para onde ir. Nas palavras de Luciana,

\begin{abstract}
A Tereza de Benguela é, para nós, uma referência de luta e resistência. Ela e o marido fizeram a resistência no Morro do Piolho no Mato Grosso e, depois que mataram o marido, ela se uniu aos negros alforriados fugitivos e aos índios. $\mathrm{O}$ quilombo cresceu e resistiu por mais de duas décadas. Infelizmente ela foi capturada, estuprada e degolada. Sua morte, em 25 de novembro, marca o Dia Mundial contra a Violência Doméstica. A nossa ocupação foi inaugurada no mesmo dia e, por isso, lutei para que tivesse o nome de Tereza de Benguela.
\end{abstract}

Diferente de Tereza, Luciana e outras mulheres continuam resistindo e, em seu nome, permanecem mostrando a força que é possível retirar do desconforto, da adversidade e da privação para se (re)construir e fazer uma nova história! Para além de moradias para essas mulheres, a ocupação Tereza de Benguela se constituiu em uma morada, onde não se milita apenas por casas, mas pela (re)construção de corpos, identidades e dignidades.

Curiosamente, pouco se falou sobre feminismo, algo que surgiu na experiência de Luciana tardiamente. No dia da entrevista, contudo, ela levava consigo o livro "Feminismo em comum", de Márcia Tiburi, denotando inquestionável vontade de saber. Vestia ainda como acessório um lenço verde que envolvia seu pescoço e remetia à luta pelo direito ao aborto, que à época estava em discussão na Argentina e, posteriormente em audiências públicas no Congresso Nacional Brasileiro. A narrativa de Luciana era composta por muito mais que as palavras proferidas e sua elaboração nos fez lembrar as 
palavras de Ecléa Bosi: "Essa ordenação obedece a uma lógica afetiva cujos motivos ignoramos; enfim, recontar é sempre um ato de criação." "13.

Ficava claro que aquela história ainda tinha muita estrada para percorrer e que a luta por moradia podia ser o mote, mas que não se esgotava nisso. Ali os corpos estavam em evidência e constituíam a morada de ideias e ideais.

\section{Considerações finais}

As reflexões apresentadas no presente artigo partem de um projeto coletivo que reuniu pesquisadoras do Grupo de Pesquisa em Gênero e História do Departamento de História da USP no ano de 2018 e que tinha como objetivo central promover uma atividade que extrapolasse o âmbito estritamente teórico. Foi experiência enriquecedora para todas as participantes, envolvendo aproximação de um grupo de mulheres cujas trajetórias se distanciam das nossas, mas nos inspiram a estabelecer novas relações de significados com os estudos de História das Mulheres e das relações de gênero a partir de demandas existentes no tempo presente.

Entre visitas a ocupações, participação em atividades do grupo militante, discussões de textos teóricos e metodológicos, as entrevistas concretizaram a proposta e permitiram avançar em análises mais profundas sobre a realidade da luta por moradia, nas especificidades vivenciadas pelas mulheres. Aprendizados inestimáveis agora fazem parte de nosso percurso como pesquisadoras e a proposta, por ora interrompida, guarda possibilidades de ser retomada em momento oportuno, sobretudo, para as colaboradoras. Na luta por moradia, em que mulheres ressignificam seus corpos como espaços de mobilização, foi possível acompanhar múltiplos sentidos nas ações empreendidas pelo grupo e suas diferenças em relação às demandas vislumbradas pelos homens. O empenho em acolher e compreender as necessidades das mulheres em situação de vulnerabilidade torna suas realidades mais amplas que o desejo individual de conquistar uma casa própria. São vários corpos em ação que se constituem em moradas para acolher outros corpos e concretizar objetivos de vida.

Data de submissão: 06/05/2020

Data de aceite: 07/07/2020

\footnotetext{
${ }^{13}$ BOSI, Ecléa. Tempo vivo da memória: ensaios de Psicologia Social. São Paulo: Ateliê Editorial, 2003.
} 
Referências Bibliográficas

BIROLI, Flávia. Gênero e Desigualdades: limites da democracia no Brasil. São Paulo: Boitempo, 2018.

BOSI, Ecléa. Tempo vivo da memória: ensaios de Psicologia Social. São Paulo: Ateliê Editorial, 2003.

JESUS, Carolina Maria de. Quarto de despejo: Diário de uma favelada. São Paulo: Ática, 2014.

MEIHY, José Carlos Sebe Bom. RIBEIRO, Suzana Lopes Salgado. Guia Prático de História Oral. São Paulo: Contexto, 2011.

PERROT, Michelle. Os excluídos da História: operários, mulheres, prisioneiros. Rio de Janeiro: Paz e Terra, 2001.

SAFFIOTI, Heleieth. Gênero, patriarcado, violência. São Paulo: Expressão Popular: Fundação Perseu Abramo, 2015.

TRAT, Josette. Movimentos Sociais. In: HIRATA, Helena; LABORIE, Françoise; LE DOARÉ, Hélène; SENOTIER, Danièle (Orgs). Dicionário Crítico do Feminismo. São Paulo: Editora UNESP, 2009.

WOOLF, Virgínia. Um teto todo seu. São Paulo: Tordesilhas, 2014. 